\title{
Editor's introduction: Qualitative research in the course of a pandemic
}

\author{
Lodovico Balducci \\ Senior Member Emeritus, Moffitt Cancer Center, Tampa, FL, USA
}

In the course of unexpected and overwhelming events such as the ongoing COVID-19 pandemic qualitative research based on narrative inquiry may provide unique and vital insights. It identifies individual survival parcourses with universal valence. These parcourses are all but lost in traditional medical, psychological, and social research that overlooks individual experiences, classifying them as background noises. From these very noises qualitative research extracts the sound of coping mechanisms that allow a person to come to term with his or her own personal tragedy even if death appears all but unavoidable.

An example of such itineraries is provided in the memoir of Primo Levi. ${ }^{1}$ Levi faced death every minute of the two years he spent as a prisoner in Auschwitz. He succeeded in dissipating his own fears and in encouraging his prison mates by rehearsing and quoting Dante's poem ${ }^{1} \mathrm{La}$ Divina Commedia (The Divine Comedy) where Ulysses reminds his shipmates that no one can rob them of their dignity. This anecdote that inspired victims of wars, persecutions, and natural disasters around the world would have been lost in the official accounts of the Holocaust. The articles that follow emphasize that it is always possible to find a pathway to heal one's illness even when scarcity of resources withstand medical management.

The other fundamental role of qualitative research consists in a more complete analysis of the response to the crisis. The scope of the analysis includes individual impressions and experiences that highlight unsuspected

Correspondence: Lodovico Balducci, Senior Member Emeritus, Moffitt Cancer Center, 4128 Carrollwood Village Dr, 33618 Tampa, FL, USA.

Key words: COVID-19; pandemics; qualitative research; ethics; solidarity, religion.

Conflict of interest: The author declares no conflict of interest.

Received for publication: 11 December 2020.

Accepted for publication: 29 December 2020

This work is licensed under a Creative Commons Attribution NonCommercial 4.0 License (CC BY-NC 4.0).

${ }^{\circ}$ Copyright: the Author(s), 2021

Licensee PAGEPress, Italy

Qualitative Research in Medicine \& Healthcare 2021; 5:9686

doi:10.4081/qrmh.2021.9686 strengths of the system as well as unknown weaknesses. Some of the articles that follow highlighted the sense of solidarity and mutual responsibility among health care workers. Under managers who lead by example this solidarity may become the main resource at a time when confusion prevails and individual roles are muddied.

At the mean time an emergency of long duration presents new challenges that involve the burnout of the caregivers, the rationing of limited resources, the economical and emotional impact on the general population. While it may not provide a response to each dilemma, qualitative research puts a human face on each challenge and comforts the practitioner. Some quandaries, such as the rationing of care, may be insoluble. In this circumstance any decision guided by compassion is the best decision.

This issue of Qualitative Research in Medicine and Healthcare is dedicated to COVID-19. We collected the testimony of health professionals who have been both patients and caregivers. Based on their embodied experiences, the authors illustrate the healing trajectories available to victims and caregivers of the victims, not only during a pandemic but throughout catastrophes of any type.

The pandemic has caught us unprepared at a medical, social, and emotional level. The Western culture held outbreaks of this size all but impossible in the so-called developed world. Widespread hygienic norms should be able to prevent contagion by infectious agents, and a science able to dissect the human genome may certainly find a remedy against new organisms. These expectations might be legitimate, but they need to be placed in a realistic context defined by human reactions and practical conditions. Let's start with precautional measures. Social isolation proved out of reach for overcrowded residences, ${ }^{2}$ for retirement homes, ${ }^{3}$ and for most work related activities that could not be conducted from a distance. Face masks and vaccines are only as good as the willingness to adopt them ${ }^{4}$ and as long as the demand does not overwhelm availability. The development of vaccines and therapies requires time, and during this time the availability of hospital beds, life-supporting devices, and health care providers ${ }^{5}$ may become overtaxed. And it is currently overtaxed in some areas of the country such as Southern California.

The economic duress caused by the pandemic may delay the treatment of coronavirus as well as of other diseases and may even cause food uncertainty. ${ }^{6}$ The emotional cost of COVID- $19^{7}$ has not been fully evaluated yet, 
but we know it includes anxiety, depression, post-traumatic stress disorder and may lead to outbursts of domestic and community violence. Naturally medical, economical, and emotional issues have influenced each other creating a multidimensional self-aggrandizing crisis.

Our overreliance on science to prevent a pandemic proved misguided and now scientists foresee that even worse pandemics may be on the horizon. The exploration of human reactions and individual pathways to survival and healing through narrative could not be more timely.

Germane to narrative based research on COVID-19 are previous literary descriptions of pandemics. Literature and arts have dealt with pandemics of the past and in some cases they have used pandemics as background of novels. ${ }^{8}$ It is important to ask what the present articles may add to the existing material. We will mention the works that appear more relevant to the current situation.

The so called "black plague" that ravaged Europe between the fourteenth and the seventeenth century represented the most quoted literary model of a pandemic and has inspired two major Italian novelists, Giovanni Boccaccio and Alessandro Manzoni. The Decameron (from the Greek Ten Days) by Boccaccio is a collection of a hundred short novels narrated over ten days by ten youths in the outskirts of Florence, where they had fled the plague in the fourteenth century. I Promessi Sposi (The Betrothed) is a long novel that takes place in the seventeenth century in Northern Italy and contains a description of the $17^{\text {th }}$ century plague in Milan, Italy. One is surprised of finding many similarities between events occurring centuries ago and the current epidemic of COVID-19. In both reports the initial signs of the contagion had been disregarded and so were the precautionary measures (the face mask of our time) and the impact of the epidemic had been underestimated. In both cases the plague brought social havoc and economic disruption. In both cases people unable to find a solution on their own recurred to God. But in Manzoni's account the religious ceremonies led to increased spreading of the plague (does it sound familiar?). Manzoni also describes the procession of carts carrying the dead to common tombs, (something we saw today in Italy and in Brazil and something comparable to the makeshift morgues of New York) and the conspiracy theories that led to the death on the pyre of innocent individuals (the so called untori, 'greasers') accused to spread the contagion by greasing the pews of churches and the doors of buildings with infectious material.

Manzoni's account includes several vignettes, of which the most heart wrenching is the description of a mother consigning to the monatto (undertaker) the corps of her 7-years-old daughter Cecilia, dressed in her feast dress and perfectly combed. The mother bribed the monatto to take particular care of her precious child, that she greeted with arrivederci (to see you soon). Though they may be literary masterpieces none of these vignettes describe personal trajectories toward coping with the plague. The accounts of Boccaccio and Manzoni describe the medical and social landscape in terms that appear relevant to the COVID-19 pandemic but do not include the personal attitudes that are the object of the present issue of the journal.

The Algerian Nobel Prize winner Albert Camus wrote La pest (The plague) in 1947. In this novel the author imagines that an epidemics of plague causes the cloture of Oran, a middle sized Algerian town. The characters of the story are multifaceted and realistic, but the main focus of the author is to express his philosophy through them. Camus was an atheist existentialist, longing for a religious faith. He regretted of being unable to believe in God. In the novel the character of Mr. Tarrou reflects the personality of Camus himself. Mr. Tarrou is an atheist who aspires to become a saint even in the absence of a deity. To this end he succeeds in inspiring a sense of solidarity in the population of Oran. A common goal allows the populace to overcome the desperation brought on by the epidemics and to discover a sense of personal closeness. It also leads to the mobilization of unsuspected social resources for the management of the plague. As we will see this experience is germane to the experience of health professionals caring for COVID-19 patients.

A relatively small number of American novels have the Spanish Influenza as background. Of these may be worth mentioning John O'Hara: The doctor's son (1936). The author was indeed the son of a physician who took care of influenza patients during the pandemic in a small mining town. He highlights that the more likely victims of the pandemic were the underprivileged living in poverty, a finding germane to the current pandemic. The author did not have the opportunity to appreciate the relation of advanced age and mortality, because at that time the general population was much younger and the percentage of individuals over 60 was minuscule.

Perhaps the document more relevant to our issue of the journal is American Life Stories: Manuscripts from the Federal Writers Project 1936-1940 that contains 2847 stories related to the Great Depression. Many of them report personal accounts of the flu epidemics. The narratives were collected by a number of writers and were organized by John A. Lomax, Benjamin A. Botkin and Morton Royce, and may be accessed online. The account of nurse Alice Duffield from Arkansas, narrated by Lisa Taylor with the title $A$ woman on duty, is particularly compelling. It talks of corpses spilling out of overcrowded morgues. It talks about black and white workers walking together in then segregated Arkansas. And she describes how her nurse manager scolded her for crying in private. Given the emergencies there was no time to waste in the expression of private distress.

This collection of snapshots of the Spanish Influenza epidemic may indeed be an invaluable mine of information for qualitative students and may to some extent complement our findings. Yet I believe our contribution to the 
literature is unique in two respects. It represents an account of recent experiences rather than of decade old memories. It follows the established rule of narrative based qualitative research.

Two of the articles report the experience of health professionals who caught the disease themselves. Leo Begazo $^{9}$ is a nurse manager in a major USA cancer center. He disregarded the initial symptoms of COVID-19 as if they represented a common viral infection and only when he had developed significant respiratory distress sought admission to the hospital that led to mechanical ventilation, requiring medically-induced coma. Most likely his disease was cured by the experimental drug tocilizumab that Leo received as part of a clinical trial. He learned three major lessons that will inspire his practice from now on. He experienced healing when two nurses agreed to pray with him prior to intubation. He realized that even if he had not survived he was at peace with himself and death did not scare him anymore. In other words he learned that healing is a personal experience and is always achievable even in the absence of a cure. From now on healing will be the ultimate goal of the care he is going to provide to cancer patients. He realized that the love of his family and friends who insisted that he fight the disease to the end has been the key to his cure. Without this support he probably would have forfeited mechanical ventilation when his situation deteriorated and without ventilation he would have not been able to live long enough to receive the drug that saved his life. He wishes to emphasize how important it was in this respect the attitude of the hospital staff. They treated him with respect, acknowledged him as a colleague, and obliged his request to pray with him. They facilitated the interaction with his family via video, and they surrounded him with affection as well. In his own words they "treated him as a person with COVID-19 and not as a case of COVID-19." From now on he will make sure that each patient finds the most favourable conditions to a good outcome. He will treat all patients with the same respect he received, will not shy away from praying with them and will encourage family and friends to express their affection in the most convincing way.

As an oncology nurse he knew a lot about death. Yet he was surprised that his reaction toward the threat of death was fear rather than anger, as he had expected. He realized that the reaction to death may vary with the situation. A cancer patient who learns to have a limited time to live but his/her death is not imminent has the time to go through all the stages of death described by Kubler Ross..$^{10}$ The situation is quite different for a person facing imminent and unexpected death. ${ }^{11}$ In this situation a number of different feelings compete with each other, including fear of death, apprehension for the survivors, worry for unfinished tasks, sorrow for missing a promising future. And of course death may come unexpected also to cancer patients due to an intercurrent disease or accident or to treatment complications. In these situations the most appropriate action of the provider may include listening, allowing the patient to unravel the different emotions and addressing the prominent ones.

Stefano Leccardi ${ }^{12}$ is a specialist in pulmonary diseases who currently works as a hospitalist in a general hospital in Northern Italy. He lived the epidemic as a provider and as a patient: after taking care day and night of COVID-19 patients he caught the infection himself and like Begazo he had been threatened by imminent risk of death from respiratory failure.

The outburst of the epidemic led to an unexpected and most welcome outpouring of human solidarity among the hospital staff that inspired each person to work to the best of his/her ability, out of a sense of service. One may say that the epidemic allowed them to discover the satisfaction and the pride to care for other human beings. When asked to be part of the COVID management team Stefano had no second thought, despite the risks and the inconvenience involved. He realized to be endowed with unique expertise to manage these patients and lived his service as a privilege. The time had come for him to pay back a world that had been most gracious and welcoming to him. Perhaps Lucia, the nurse manager of his ward had the most important influence in promoting solidarity. Together with her spouse and her children she decided to table the beloved family outings and instead to make a family project of the management of COVID. Without extra compensation Lucia was working fourteen daily hours every day of the week, always with a smile. She did not ask the staff to provide extra work, but her example elicited what Leccardi calls "a joyful competition" among the staff members to provide extra service. And perhaps to talk about solidarity is limitative in scope. When the mother of a physician died all her colleagues offered to cover her work shifts. When she came back to work, she stated she felt surrounded by love. It may be impossible to define love in words, but it is something one recognizes when he/she sees it.

When the ward became overwhelmed the health department mandated that the ICU be reserved for individuals younger than 75 . It was a legitimate decision that contrasted however with the principle of justice, one of the four pillars of medical ethics. Leccardi does not try to afford this vexing dilemma. Instead, he acknowledges that the practice of medicine in the presence of an emergency may involve insoluble predicaments. It would have been inappropriate for a provider to decide on his/her own to prioritize which life to save. But a society has the right to manage limited resources and providers may obey governmental directions, without compromising their ethical principles.

Like Begazo, Leccardi faced imminent death. Like it was the case with Begazo, the threat of death allowed him to widen his scope of healing, to learn that healing is an always reachable personal settlement even when cure is 
out of reach. ${ }^{13}$ Perhaps inspired by the psychiatrists in his family (his mother and his late brother) he introduced the concept of the wounded healer ${ }^{14}$ originally formulated by Carl Jung. Leccardi felt that his flirtation with death gave to him a special credibility to bring healing to incurable patients. Finally, like Begazo, Leccardi credited his recovery as much to the love and care he was surrounded with as he does to his medical treatment.

The article by Hernandez et al. ${ }^{15}$ illustrates an ethical dilemma that might have been unknown during previous pandemics. An ethical consult was requested concerning a 42-year-old woman who had developed COVID-19 after a bone marrow transplant for the management of acute leukemia. It is important to highlight that the patient belonged to an ethnic minority, that appeared more susceptible to the infection. At the meantime minority individuals are more likely to suspect that providers may shortchange them of their best care. Indeed, the patient had refused in multiple occasions to provide advanced directives about her health care. On admission she was unable to express her wishes because of encephalopathy and her husband was by default her health care surrogate.

Since her admission, the situation appeared hopeless, because she had bilateral pneumonia and was neutropenic as a result of her recent transplant. Nonetheless, she received all available treatment including Tocilizumab, Remdesivir, convalescent plasm and steroids. The situation became more complicated because of a pneumopericardium that would have required a surgically placed drainage, but the procedure was judged too risky, and the development of disseminated herpes infection. The spouse and the father were originally reluctant to discontinue life supporting care. Rather than making the decision to discontinue all treatments because of futility, as it would have been his prerogative, the ethic consultant recommended a family reunion involving the children and the parents of the patient. During that reunion it was explained to the family that the life supporting treatment was prolonging the patient's death and the family unanimously agreed that the most compassionate course of action included trusting the patient to comfort care.

This case is emblematic of our times for medical and cultural reasons. This lady had received organ transplantation, a procedure that might have cured her leukemia, but had made her more susceptible to infections. Organ transplantation is becoming every day more common and so is the number of vulnerable patients. But even without bone marrow transplantation modern medicine has allowed the survival of more and more individuals likely to succumb during an epidemic. Many cancer patients are among them. This lady belonged to an ethnic minority that had been underserved by medicine and she and her family were afraid of being shortchanged as it had happened in the past and may still happen. This situation is also likely to become more and more common given the increased diversity of the world population. Of particular concern is the large number of undocumented immigrants that may delay the quest of treatment out of fear of being incriminated. In the course of an epidemic they may become a reservoir of infection.

The ethical team was culturally sensitive and led to the solution of this case through compassion. This case emphasizes the importance of cultural competence in the management of a pandemic, especially since the minority population is the most vulnerable.

All articles deal with religious beliefs that may also lead to healing. Organized religion may provide social resources in addition to the personal ones and it behooves the practitioner to discover these resources that may include economical and emotional support, childcare and help in the instrumental activities of daily living. In a pandemic these resources appear particularly relevant. Nobody would advocate exploiting the pandemic in order of influencing people's beliefs. Nobody nowadays would support the situation described by the Italian director Vittorio De Sica in the movie Umberto $D$ where an old retiree agreed to recite the rosary daily to gain the benevolence of the nurse manager, who was a nun. We are talking about unearthing all existing resources to make most effective the treatment of the seriously ill.

What we have learned from these reports?

Two health care providers discovered the full scope of healing and plan to make of healing the main focus of their practices. This lesson is far from new, but it is worth repeating, because healing is a personal experience reached through a personal parcourse and each parcourse is new to some extent. For Begazo prayers led to healing, for Leccardi the discover of healing coincided with the discovery of the ultimate sense of human life. Both of them emphasize the importance of personal care, of the respect of human dignity, and of spirituality for the achievement of healing. Both conclude that it is necessary to learn to coopt death as a human experience to be able to heal. If death is the ultimate enemy the whole humanity is doomed to failure.

By way of his personal experience Leccardi confirms the literary hypothesis of Mr. Tarrou in Camus' The Plague that a major event like a pandemic may reveal unsuspected reserves of human solidarity as well as of professional energy. To unearth these reserves, leaders need to lead by role modeling rather than commanding. Leccardi goes a step farther and recognizes that role modeling is made possible by unconditional love, that is, love that looks for no other remuneration but service itself. This consideration expresses a challenge to a culture that considers personal profit the primary motivation of any human action and the satisfaction of personal feelings the only worthwhile goal. A common tragedy reminds us "not to ask for whom the bell tolls. It tolls for thee." During the pandemic we learned that if we can't live together we will have to die together.

The pandemic elicited a number of ethical questions, 
such as rationing of care and provision of futile treatment. The answer to these questions needs to be based on ethical principles but adapted to the practical circumstances. Rationing of care as a provider's choice is unacceptable, but at the same time it behooves the practitioner to heed the directions expressed by governmental agencies that represent the will of society. The provision of futile care is wrong, but the discontinuance of any care needs to be planned through a compassionate decision involving the patient's family.

All the articles emphasized the role of religion as a personal and social resource. While we certainly honor these testimonies, I believe they should be generalized by saying that healing is a spiritual experience and a practitioner should learn how to utilize the existing spiritual resources of which the CPT trained hospital chaplains are the most reliable.

Without affording all the issues related to the management of coronavirus I hope that this issue of the Journal will become an incentive for other professionals to share their experience and creating individual trajectories to healing in the course of a pandemic.

\section{References}

1. Levi, P. Se questo è un uomo. Torino, Italy: Einaudi; 1955.

2. Abuelgasim E, Saw LJ, Shirke M, et al. COVID-19: Unique public health issues facing Black, Asian and minority ethnic communities. Curr Probl Cardiol 2020;45:100621.

3. Abbasi J. Social Isolation-the Other COVID-19 Threat in Nursing Homes. JAMA 2020. Online ahead of print. doi: 10.1001/jama.2020.13484.
4. Cheng VC, Wong SC, Chuang VW, et al. The role of community-wide wearing of face mask for control of coronavirus disease 2019 (COVID-19) epidemic due to SARS-CoV-2. J Infect 2020;81:107-14.

5. Firew T, Sano ED, Lee JW, et al. Protecting the front line: a cross-sectional survey analysis of the occupational factors contributing to healthcare workers' infection and psychological distress during the COVID-19 pandemic in the USA. BMJ Open 2020;10:e42752.

6. Okonkwo NE, Aguwa UT, Jang M, et al. COVID-19 and the US response: accelerating health inequities. BMJ Evid Based Med 2020. Online ahead of print. doi: 10.1136/bmjebm-2020-111426.

7. Torales J, O'Higgins M, Castaldelli-Maia JM, Ventriglio A. The outbreak of COVID-19 coronavirus and its impact on global mental health. Int J Soc Psychiatry 2020;66:317-20.

8. Keys TE. The plague in literature. Bull Am Library Ass 1943;32:35-56.

9. Begazo L. From nurse to patient: A journey to healing. Qual Res Med Helathcare 2021;5:9689.

10. Kübler-Ross E. On death and dying. Bull Am Coll Surg 1975;60:12:15-7.

11. Heymann EP, Wicky A, Carron PN, Exadaktylos AK. Death in the Emergency Department: A Retrospective Analysis of Mortality in a Swiss University Hospital. Emerg Med Int 2019;2019:5263521.

12. Leccardi S. COVID-19: A learning moment for patients and health professionals. Qual Res Med Helathcare 2021;5:9688.

13. Byock IR. The nature of suffering and the nature of opportunity at the end of life. Clin Geriatr Med 1996;12:237-52.

14. Gonzales M, Melton L. The Wounded Healer. J Adv Pract Oncol 2017;8:453-5.

15. Hernandez J, Lubrano diCiccone B, Thirlwell S, BoothJones M, et al. COVID-19 pandemic causing medical and public health ethical dilemmas: A case report and review of literature. Qual Res Med Helathcare 2021;5:9690. 